\title{
The Scholarly and Pathic Cavalier: Max van Manen's Phenomenology of Practice
}

\author{
Peter Willis, University of South Australia \\ Peter.Willis@unisa.edu.au
}

It is much easier for us to teach concepts and informational knowledge than it is to bring about pathic understandings. But herein lies the strength of a phenomenology of practice. It is through pathic significations and images, accessible through phenomenological texts that speak to us and make a demand upon us that the more non-cognitive dimensions of or professional practice may also be communicated, internalised and reflected upon. For this we need to develop a phenomenology that is sensitive to the thoughtfulness required in contingent, ethical, and relational situations (van Manen, 2014, p. 269).

\section{Introduction}

I received Max Van Manen's book, Phenomenology of Practice: Meaning-giving methods in phenomenological research and writing for comment some months ago and have been digging into it over the intervening weeks with a strange mixture of delight and despondence: delight in the discoveries revealed in this rich offering; despondence at the task of doing a reasonable job of reviewing such a formidable contribution to contemporary scholarship relating to human practice, to purposive human action. So, I come to this essay as a practitioner scholar exploring ways in which this text is accessible and useful as a contemporary working text for practitioner scholars. I have long been impressed by van Manen's writing around phenomenology of practice and attracted to his literary style in verbal and textual exposition. Irene Madjar in her review of this same text was able to point to the author as maestro and to pursue her review in a very similar vein to mine. "Max van Manen is a great teacher and a true maestro in the craft of phenomenology and phenomenological writing" (2014, p. 719).

One of the fascinating and frustrating features of this tightly written and searching text is that I have found it very difficult to paraphrase his ideas for this review without at least a frisson of concern that my paraphrase may not have carried all that well from the author to my text. I have realised that van Manen's textual style, with its poetic structure and cadence, has analogous similarities with compressed texts of poetry and one would hesitate to paraphrase a poem. Citations from the book are referenced as 'PoP' followed by the page number.

\section{Cavalier and Roundhead}

One of the contextual elements of this review in contemporary scholarship is the historical cleavage between what I have called Cavalier and Roundhead approaches to phenomenological inquiry. The Cavalier approach with its flair and aesthetic 'dwelling' on a phenomenon hopes to uncover meaning by attending to the knowing process at its early moments, its 'gut feeling' response before the knower moves to analyse and name the phenomenon through the usual reductive, categorising process. 
The Cavalier is interested in poetic and metaphoric approaches to a phenomenon as significant tools in the qualitative research process. The approach of van Manen, whose writings have much of the Cavalier in their careful, poetic texture, was already present in his earlier book Researching Lived Experience (1997). It encouraged oblique ways of writing, (anecdotes were often employed) in which the phenomenon could be caught sight of and, at least to some extent, understood in its raw 'initially connected' state through tentative, aesthetic processes.

The Roundheads approach, under the banner of strictly interpreted Human Science (as distinct from Natural Science) seeks to validate a claim to another kind of science and empiricism by building an account of a phenomenon using a kind of structured process, a scaffolded rigorous 'scientific' approach, using 'descriptive analytical procedures' (PoP, p.211). One of the established authors in this vein is Amadeo Giorgi in the USA and more recently Jonathon Smith in UK. Van Manen's point which he does not labour, is that phenomenology of the unspoken experience of initial encounter cannot readily be achieved using descriptive, analytical procedures and he indicates that this is not in the purview of his book.

\section{An Agogical Approach to Reading the Text}

I hope to be able to mirror van Manen's agogical approach as I, in the company of an imaginary research student, begin to trek through the book making working notes of its offerings. As van Manen himself writes,

An agogical approach tries to be an example of what it is showing - a writing practice for those who are interested in doing phenomenological research and writing. An agogical approach to phenomenology aims to guide the person to the project and pathos of phenomenological inquiry and to help stimulate personal insights, sensibilities and sensitivities for a phenomenology of practice. (PoP, p.19)

\section{Questions of Order}

Following the logical flow of the ideas in this book, the chapters concerned with actually doing phenomenological writing are placed at the end after reflections on the many dimensions of the phenomenology. These, chapters 13 and 14, provide a kind of tangible, concrete visibility to the kind of writing he describes and espouses, which is such a helpful element in this book.

The only agogical intervention that I as practitioner and research supervisor might want to pursue is to invite new researchers and scholars to read chapter 13 and 14 mentioned above, early in their reading of this volume not necessarily with intense, detailed scrutiny as with a kind of reflective open attention. I think this is what pathic phenomenologists would be seeking to sustain by keeping a kind of 'listening attention' to the phenomenon and allowing this attention to come to expression in appropriate words, images, anecdotes.

Once there is a kind of 'concrete' knowledge of phenomenological writing, which is so clearly laid out in the last chapters, the enchanted writers-to-be can then be seriously interested in examining the underpinning ideas behind these forms of writing and can head back to earlier parts of this book.

The comprehensive table of contents provided here, in which each chapter and section within the chapters are named, is of great value. Students will be able to scan and close in for deeper engagement in one point or another in their reading and reflection. There is such 
extraordinary depth and breadth in his treatment of various authors and their variations that his volume is likely to be used and consulted many times by scholars and students.

\section{Chapters}

The 390 pages of this book are divided into 14 chapters. The first is an overview entitled 'Phenomenology of practice' which teases out the project of the book which is to explore a phenomenology of professional and informal purposive action. "A phenomenology of practice does not aim for technicalities and instrumentalities - rather it serves to foster and strengthen an embodied ontology, epistemology, and axiology of thoughtful and tactful action" (PoP, p.15).

Chapters 2 to 7 deal with foundational questions concerning the nature of phenomenology and its many variations effectively since the time of Husserl. Following his agogical approach, van Manen takes the reader into the thinking underpinning various kinds of phenomenological inquiry and the direct link with understanding human meaning making in purposive action or practice.

The second chapter on Meaning and Method is a detailed and carefully argued exploration which seeks to orient the reader to the history and emergence of the phenomenological project. This leads to three chapters devoted to writers and thinkers who have engaged with phenomenology in different ways. I was impressed to see Edith Stein, one of Husserl's protégés given such careful and appreciative treatment.

Chapter Eight gets down to applied philosophical methods and guides the reader into Epoché and Reduction. This chapter is helpful indeed. The phenomenological researcher is encouraged to dwell on the phenomenon (reduction) while at the same time refusing to allow space for pre-judgments and theories already somehow present in the mind (bracketing or epoché). As van Manen says, "It is helpful to keep in mind the underlying idea and purpose of the reduction: to gain access via the epoché and the vocative, to the world of pre-reflective experience-as-lived in order to mine its meanings" (PoP, p. 221).

The following chapter, Chapter 9 on the Philological methods: The vocative is another powerful unveiling where van Manen sets out to explore appropriate textual forms which can be used in the pre-analytical stage of knowing. He addresses this with great depth under four headings: Lived Throughness, Nearness, Intensification, Pathic and Epiphany.

In Chapter 10 van Manen moves to an imaginary coal face where a new project is being considered. He reminds scholars of the conditions under which phenomenology is an appropriate research approach. Thus again, true to his 'agogical' agenda, he invites researchers to examine their projects in the light of their suitability for phenomenological inquiry. It is in this chapter where he revisits the helpful existential methods drawing on Merleau-Ponty's Phenomenology of Perception and refers to his own work on childhood secrets. He writes, "How can the existentials of relation, body, space, time, and thing guide us in exploring the meaning structures of the experience of secrecy" (PoP, p.303). This is followed by Chapter 11, on empirical and reflective Human Science methods of inquiry which is clear and challenging. Chapter 12 looks at issues of logic and the criteria by which phenomenological inquiry can be evaluated.

Page 355 has a brief summary of criteria for evaluative appraisal of phenomenological writing. This brief summation can also be understood as a succinct and useful profile of a good phenomenological text: Heuristic questioning, descriptive richness, interpretative depth, distinctive rigor, strong and addressive meaning, experiential awakening and inceptual epiphany. 


\section{The Work of Phenomenological Writing}

This leads to questions of phenomenological writing mentioned earlier in this review that are a 'must read' for aspiring scholars, and which contain many luminous, seriously useful writing guidelines. Chapters 13 is about writing phenomenologically, and Chapter 14 is about drafting such writing.

Aspiring students caught up in phenomenological inquiry and wishing to create a strong research text might want to transcribe the following insightful and challenging paragraph:

When a text is successful, and when the reader is open to it, then the text may have an effect which is almost inexplicable. The words literally take the reader or listener into a wondrous landscape, evoking a feeling of disorientation, causing confusion that tends to accompany the experience of strangeness, of being struck with wonder. (PoP, p. 359)

Van Manen's criterion bears significant similarity with that used to evaluate the power and insight of poetry and its capacity to stop readers in their tracks. He pulls no punches. People wanting to enter into the world of phenomenological text-making must be aware that this kind of writing has a high 'degree of difficulty and risk' so that if not successful, the fall from achievement is unavoidably visible and inescapable. Students attempting to create poetic verse in their qualitative research writing, who have never done anything like it before, will be confronted with visible and embarrassing disasters and should be encouraged to take a less difficult road.

For this practitioner reviewer who has been attempting phenomenological inquiry for some years, these later chapters are of great importance. Although van Manen (1997) had written about these practical matters in his earlier book: Researching Lived Experience, the more detailed exposition of different elements of method and meaning in this book are robust, relatively accessible and challenging. There is an extraordinary depth in these pages. In the intervening years since the research handbook, van Manen has continued to teach and supervise phenomenological projects and to write and curate various combined publications. It is the sureness of his writing, particularly about human practice, that makes this volume such a remarkable find.

While there is not space to review and explore every significant element in this extraordinary book, I want to note a few significant theme-terms which appear like building blocks in van Manen's opus.

\section{Meaning and meaning giving}

The terms 'meaning-giving methods' in the title require clarification. It is not 'meaning discovering' but 'meaning giving' is the term van Manen favours. At the same time he writes that

Just like the physicist is driven by a certain pathos to penetrate the cosmic-quantum secrets of the physical world, so the phenomenologist is driven by a pathos to discern the primordial secrets of the lived meanings of the human world. (PoP, p. 17)

On the last line and over the next page he writes that, "Phenomenology gravitates to meaning and reflectivity. The latter is caught up in a self-reflective pathos of reflecting, discerning meaning in sensing the world of things, others and self" (PoP, p.18).

As far as I can construe the author's ideas, there is thus a tension between meaning discerning where the meaning is already to some extent embedded in conscious human practice 
and meaning giving where the meaning has not been overtly realised. It is this 'meaning discernment' and 'meaning giving' which is the work of phenomenology as explained by van Manen.

\section{Pathos}

At one of the nursing research conferences in Australia, at which van Manen was the key-note speaker, he gave an arresting lecture on 'the gnostic and pathic hand'. I was present and noted the sense of enrichment in the animated conversations at coffee after the lecture. Van Manen had revealed and brought to life the distinctive character and depth of the nurses' lived experience of their specific caring and healing engagement with patients. While the 'gnostic' dimension with its link to 'diagnosis' seemed readily understood, the pathic hand and the pathic experience were revealed as so much more than a kindly, affirming touch. The pathic hand was the hand of someone who was bodily and emotionally present to the patient as a 'whole person with an illness' rather than an embodied illness where healing the illness was foregrounded and the humanity of the patient given little acknowledgment.

One of van Manen's illuminations is his exploration of this 'pathos' which contains within it a useful idea of holistic engagement in life, in service and in action. Again he can array references to a kind of engaged detachment not too coloured by individual prejudice, but a sense of tactful presence. "The phenomenological pathos is the living project of bringing all the living of life to meaningful expression through the imageries and languages of phenomenological writing, composing, and expressing" (PoP, p.18).

Later in the book, van Manen reflects on the capacity of phenomenological texts to evoke pathic understandings. This quotation was used as the epigraph at the beginning of this review,

It is much easier for us to teach concepts and informational knowledge than it is to bring about pathic understandings. But herein lies the strength of a phenomenology of practice. It is through pathic significations and images, accessible through phenomenological texts that speak to us and make a demand upon us that the more non-cognitive dimensions of our professional practice may also be communicated, internalised and reflected upon. For this we need to develop a phenomenology that is sensitive to the thoughtfulness required in contingent, ethical, and relational situations. (Van Manen, 2014, p. 269)

This has relevance with van Manen's holistic sense of what could be called a kind of pathic pedagogy that he mentions early in the book. "So, writing a phenomenological text is a reflective process of attempting to recover and express the ways we experience our life as we live it - and ultimately to be able to act practically in our lives with greater thoughtfulness and tact" (PoP, p. 20).

\section{Questions}

There is so little to question in this detailed, rich and helpful book. There are occasional strange and unfamiliar words - the making of which has a long tradition in phenomenology: 'agogy', 'effectuated', 'addressive', 'pathognomy', 'imaginery', 'inceptual'. On the whole, the text is clear and compelling. It is like getting the full text of some great work after having worked for so long with various incomplete fragments.

Allowing that no book can encompass all, it would have been good to have seen

reference to John Heron and his book Feeling and Personhood, (1992) and the late Michael 
Crotty's work on Phenomenology and nursing research (1996). These minor omissions pale against the inclusion of so many insightful phenomenological writers particularly from Europe.

\section{Final comments}

I think the labour of this extraordinarily deep and comprehensive text should bear fruit in its immediate uptake for any researchers planning to present the lived experience of a phenomenon without drifting too quickly into conceptual analysis. The author has profoundly enriched researcher practitioners, seeking to understand and use phenomenological approaches as wonder filled poetic cavaliers enriching and complementing their more systematic and sometimes prosaic roundhead colleagues.

\section{References}

Crotty, M. (1996) Phenomenology and nursing research. London: Churchill Livingstone

Heron, J. (1992). Feeling and personhood: Psychology in another key, Newbury Park, CA: Sage

Madjar, I. (2014). Book Review: Phenomenology of Practice: Meaning-Giving Methods in Phenomenological Research and Writing. Qualitative Health Research, 24, 719-720.

Merleau-Ponty, M. (1962). Phenomenology of perception. [1945]. London: Routledge \& Keagan Paul. (Transl. Colin Smith).

Van Manen, M. (2014) Phenomenology of Practice: Meaning-giving methods in phenomenological research and writing. California: Left Coast Press.

Van Manen, M. (1997). Researching lived experience: Human Science for an action sensitive pedagogy. London, Ontario: The Althouse Press. 